\title{
Cidades em (trans)formação: impacto da verticalização e densificação na qualidade do espaço residencial
}

\author{
Cities in (trans)formation: the impact of verticalization and
} densification on the quality of residential space

\section{Maria Conceição Barletta Scussel Miguel Aloysio Sattler}

\section{Resumo}

um contexto global de urbanização crescente e de transformações acentuadas no espaço das cidades, destacam-se os processos peculiares à dinâmica das grandes cidades brasileiras, que alteram substancialmente sua configuração, promovendo rupturas no tecido urbano consolidado e nas práticas de apropriação e uso desse espaço, comprometendo sua sustentabilidade. A partir dessa perspectiva, o objetivo do presente trabalho é analisar o impacto do processo de verticalização e adensamento na qualidade do espaço residencial de um bairro de Porto Alegre (RS), promovido por alterações na legislação urbanística. Mediante estudo de caso, realizou-se análise comparativa de diferentes quarteirões, utilizando-se método de avaliação da Qualidade do Espaço Residencial (QER). Os procedimentos adotados incluem a análise de documentos, levantamentos a campo e observação direta. Apresentamse os resultados da aplicação do método de avaliação QER, em termos de qualidade do espaço da habitação, qualidade do contexto da habitação, qualidade do espaço dos serviços, qualidade dos percursos casa / serviços, apontando diferenças significativas entre quarteirões que sofreram verticalização acentuada $e$ quarteirões que mantiveram a tipologia original. A principal contribuição deste artigo reside em explorar o potencial de uso da ferramenta QER para ilustrar o impacto da aplicação de legislação urbanística, instrumentando a discussão do modelo espacial de desenvolvimento da cidade.

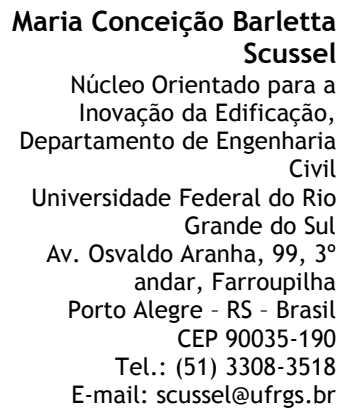

Miguel Aloysio Sattler Núcleo Orientado para a

Inovação da Edificação, Departamento de Engenharia Civil

Universidade Federal do Rio Grande do Sul

Av. Osvaldo Aranha, 99, $3^{\circ}$ andar, Farroupilha Porto Alegre - RS - Brasil CEP 90035-190

E-mail: sattler@ufrgs.br

Recebido em 15/04/10 Aceito em 02/09/10
Palavras-chave: Espaço residencial. Verticalização. Impacto ambiental.

Sustentabilidade.

\section{Abstract}

In a global context of growing urbanization and of marked transformations in cities, there are some processes that are peculiar to the dynamics of large Brazilian cities. Such processes substantially change the configuration of the cities, promoting a rupture of the consolidated urban fabric and of the practices of appropriation and use of that space, compromising its sustainability. From this perspective, the aim of this study is to analyze the impact of verticalization and densification promoted by urban legislation changes on the residential space quality (RSQ) in a neighborhood of Porto Alegre (RS). Based on a case study, a comparative analysis of different blocks was made, using a method of assessment of the Residential Space Quality (RSQ). The procedures employed include the analysis of documents, data collection and direct observation. The application of the RSQ assessment tool shows the quality of the dwelling, the quality of the $d$ welling context, the quality of services and the quality of the home-services pathways in the area, pointing to significant differences between blocks that have suffered sharp verticalization and blocks that have kept their original typology. The main contribution of this paper is to explore the potential use of the RSQ tool to illustrate the impact of the implementation of urban development legislation and support the discussion of the spatial model of development of the city.

Keywords: Residential space; Verticalization; Environmental impact; Sustainability. 


\section{Introdução}

O presente trabalho está inserido no âmbito das investigações relativas à qualidade ambiental do espaço residencial, que é o espaço onde se desenvolve o cotidiano dos moradores de uma cidade.

Num contexto global de urbanização crescente e de transformações acentuadas no espaço das cidades, destacam-se processos peculiares à dinâmica das grandes cidades brasileiras, particularmente o ritmo acelerado de densificação e verticalização desse crescimento, diante de frágeis instrumentos regulatórios.

Tais processos alteram substancialmente a configuração das cidades, promovendo rupturas não apenas no tecido urbano consolidado, mas também nas práticas de apropriação e uso desses espaços, comprometendo sua sustentabilidade. A partir dessa perspectiva, compreende-se a importância de avaliar o impacto de tais transformações na qualidade ambiental do espaço residencial.

O objetivo deste trabalho é analisar o impacto do processo de verticalização e adensamento na qualidade do espaço residencial de um bairro de Porto Alegre (RS), a partir de transformações propiciadas pela vigência do Plano Diretor de Desenvolvimento Urbano Ambiental, de 1999. Mediante um estudo de caso, estabelece-se uma análise comparativa de diferentes quarteirões de um mesmo bairro de Porto Alegre, utilizando-se método de avaliação da Qualidade do Espaço Residencial (QER), desenvolvido por Scussel (2007). Ao estender a aplicação desse método, com finalidade mais específica e limitada daquela originalmente realizada, o trabalho pretende demonstrar o potencial de utilização dessa ferramenta, contribuindo para instrumentalizar a discussão do modelo espacial de desenvolvimento da cidade.

\section{Verticalização, densificação e qualidade do espaço residencial}

Ao discorrer sobre como as cidades podem contribuir para o desenvolvimento sustentável, Satterthwaite (2004) identifica, entre as categorias gerais em que se inserem os elementos de avaliação do desempenho ambiental das cidades, a "universalização de um ambiente urbano de boa qualidade para todos os habitantes" - por exemplo, em termos do índice de área verde e da qualidade de espaço aberto por pessoa (parques, praças públicas, instalações para esporte, brinquedos infantis) e da proteção do patrimônio natural e cultural.

Nessa perspectiva, torna-se primordial o reconhecimento do espaço residencial, em que se desenvolve grande parte do cotidiano dos moradores de uma cidade, como tema central na questão da qualidade do espaço construído.

$\mathrm{Na}$ conformação do espaço residencial identificam-se três grandes componentes, ou campos de análise: a moradia propriamente dita; a infraestrutura, serviços e equipamentos urbanos; e o entorno ou paisagem. As principais variáveis de análise de cada componente podem ser descritas como segue:

(a) moradia: tamanho/densidade de ocupação; funcionalidade; material e técnica construtiva; tipo arquitetônico; estado de conservação; conforto térmico;

(b) infraestrutura, serviços e equipamentos urbanos: água: tipo de abastecimento/tratamento; esgoto: coleta/destino/tratamento; lixo: coleta/destino; luz e telefone; transportes; escola; posto de saúde; áreas verdes, praças e parques; espaços culturais: museus/bibliotecas/teatro; comércio; e

(c) entorno: ambiente construído - patrimônio arquitetônico; arborização; trânsito; ruído; ventilação; insolação - exposição solar; segurança; vizinhança.

Entre esses componentes, estabelecem-se relações que constituem parte fundamental do metabolismo diário da cidade e que são afetadas pelos padrões urbanísticos vigentes.

Os padrões urbanísticos sempre foram discutidos como grandes diretrizes conformadoras do espaço das cidades, sejam as consagradas máximas da Carta de Atenas, que imprimiu às cidades modernas o ideário das funções urbanas compartimentadas, dos zoneamentos exclusivos de usos, sejam aqueles padrões prescritos por urbanistas como Howard e Camilo Sitte, que, no século XIX, buscaram alternativas à situação de caos instalada nas cidades pós-Revolução Industrial (KOHLSDORF, 1985; RYKWERT, 2004).

Para o arquiteto Cristopher Alexander, que ofereceu importante contribuição ao desenho urbano, os padrões tornam-se elementos constituintes de uma linguagem atemporal de construção do espaço (ALEXANDER et al., 1977). Numa concepção integral e integradora do ambiente, este é definido pelo encadeamento de 
um conjunto de padrões que determinam a estrutura do espaço socialmente construído. Ao propugnar pela diversidade de usos convivendo no mesmo espaço, pela proximidade do trabalho e da casa, pela integração dos caminhos e percursos à paisagem natural, Alexander sinalizava para um conjunto de princípios adotados pela matriz da sustentabilidade, embora, à época, sequer se esboçasse formulação teórica nesse sentido. Pesquisadores a ele associados, como Salingaros (2003), trabalham, hoje, com sua consagrada premissa de que "a cidade não é uma árvore", ao defender padrões urbanísticos que tornam a cidade mais orgânica, capaz de oferecer respostas a uma realidade em que tudo está conectado - não apenas em um caminho de ramificações que se vão desdobrando, em capilaridades menores, mas em redes que se lançam em múltiplos sentidos e dimensões.

A descrição e os preceitos preconizados por essa linha de autores convergem com a defesa do padrão da cidade mediterrânea de Rueda (2002), a cidade compacta e diversa. Aqui se reúnem princípios como o da multiplicidade de usos e atividades, que encurta distâncias e busca a redução da locomoção, mediante o estímulo ao desenvolvimento de relações locais, em que habitação, trabalho e lazer estejam próximos.

Ainda segundo Rueda (2002), o modelo compacto e diverso se aproxima muito mais de uma "cidade sustentável" do que o padrão anglo-saxão de conurbação difusa, que constituiu cidades com zoneamento de funções, segmentadas, que propiciam menor interação e maiores deslocamentos e segregação.

Diferentes autores parecem acordar em eleger a cidade concentrada e densificada como mais viável (SOMEKH; LEITE, 2008; LEITE, 2010), em contraponto à cidade dispersa, do subúrbio americano, tributária das facilidades de locomoção permitidas pelo uso massivo de energia proveniente do petróleo. A partir da visão de que todas as formações urbanas, ao longo da história, foram resultado da articulação tecnológica da rede de recursos e fontes energéticas disponíveis no território, Droege (2008) aponta a necessidade de se fazer uma "revolução urbana" para que se tenha uma cidade renovável, assentada em novos paradigmas, que rompam o modelo de dependência dos combustíveis fósseis. No entanto, embora geralmente associadas, a densificação propugnada não implica, necessariamente, a verticalização acentuada como solução edilícia veja-se o caso de Paris.

Evidentemente, para além dos padrões urbanísticos, o entendimento dos processos de verticalização e densificação das cidades passa por questões vinculadas às múltiplas dimensões da produção do espaço - econômica, social, política, cultural.

Somekh (1997) aponta para a natureza das relações estabelecidas entre o arranha-céu e a cidade: não apenas volumétrica, mas essencialmente simbólica, na medida em que o edifício alto supõe desenvolvimento tecnológico, constitui manifestação das forças de mercado e implica novas formas de consumo. Os usos simbólicos da verticalidade, do domínio sobre a paisagem ao poder que multiplica o solo e os ganhos imobiliários também são abordados por Corrêa (2007).

Já Roaf, Crichton e Nicol (2009) discorrem exaustivamente acerca das características dos edifícios altos, envolvendo aspectos relativos à construção, uso, manutenção e impacto no entorno, entre os quais:

(a) custos de construção, operação e manutenção elevados, quanto mais alto for o edifício, por exigir sistemas construtivos e de proteção (contra incêndio, intempéries) mais complexos;

(b) no caso de inserção em áreas consolidadas, sobrecarga aos sistemas de infraestrutura urbana previamente existentes - abastecimento de água, esgotamento sanitário, energia elétrica, sistema viário -, além de multiplicação da demanda aos serviços e equipamentos de uso coletivo; e

(c) modificação do clima local, com aumento da velocidade dos ventos ao nível da rua, sombreamento; prejuízo ao conforto térmico, lumínico e acústico, não só do entorno mas também do próprio edifício, conforme a altura e o posicionamento de determinada unidade - quanto mais alto o edifício, maior o problema de estratificação térmica e maior o consumo de energia para climatização (ROAF; CRICHTON; NICOL, 2009).

Em estudo comparativo realizado por Souza (1994), que analisou cerca de 70 metrópoles mundiais quanto a seu processo de crescimento, São Paulo e México apresentaram características similares entre si e distintas em relação a metrópoles como Nova York, Tóquio, Londres e Paris: o ritmo de crescimento das latinoamericanas mostrou-se muito mais acelerado. Nesse processo, ao analisar o papel dos agentes produtores (incorporadores, construtores e vendedores), a autora destaca a peculiar importância da figura do incorporador na área habitacional brasileira (SOUZA, 1994).

Campos Filho (1992) discute o processo de urbanização das cidades brasileiras, identificando 
excessiva verticalização nas áreas centrais e excessiva horizontalização das periferias, atreladas às características peculiares da renda imobiliária da terra:

\begin{abstract}
O preço mais alto da terra urbana fez com que empresários imobiliários, para diluí-lo, buscassem cada vez mais a redução da cotaparte dos terrenos, [ . . . . ]. Essa superverticalização, quando não contida por lei de zoneamento e gabaritos máximos, provoca a saturação e o congestionamento dos serviços urbanos da área [ . . . ]. A elevação constante em valor dos preços dos terrenos centrais em poucos bairros privilegiados propaga-se para as periferias urbanas [...]. As cidades, por consequência, espalham-se demasiadamente, qual um queijo esburacado, podendo-se estimar que cerca da metade do espaço intraurbano no Brasil está vazio. (CAMPOS FILHO, 1992, p. 50-51).
\end{abstract}

O mesmo autor apresenta exercícios de desenho urbano envolvendo diferentes tipologias estruturadoras de quarteirões e vias, explorando possibilidades de combinar, num bairro, acessibilidade, diversidade de usos e tranquilidade para fruição do espaço de moradia (CAMPOS FILHO, 2003)

O exame da literatura permite afirmar que a verticalização, em si, não é boa nem má; o mesmo se poderia dizer da densificação que, em geral, a ela está associada. A questão é bem mais complexa e está relacionada a um conjunto de fatores custos de infraestrutura urbana, tipologia das edificações, estruturação da malha viária, etc. que, combinados, definem a qualidade do espaço urbano. Além disso, há que considerar os impactos ambientais, como os elevados gastos de energia, usualmente implicados na manutenção de grandes edifícios, além daqueles ligados à preservação da flora e da fauna, impermeabilização do solo, entre outros, apontados por Villaça (1998).

\section{Estudo de caso: um bairro em transformação}

Porto Alegre apresentava, por ocasião do Censo Demográfico de 2000, uma taxa de verticalização $\left(\mathrm{n}^{\circ}\right.$ de apartamentos $/ \mathrm{n}^{\circ}$ de domicílios) de 0,433 . Entretanto, tomada a Região Centro ${ }^{1}$, essa taxa passa a ser de 0,856 (IBGE, 2002). Embora não se disponha, ainda, de dados oficiais mais

\footnotetext{
${ }^{1}$ A Região Centro, ou Região 16 do Orçamento Participativo de Porto Alegre, reúne 18 bairros, que constituem a região mais bem equipada e estruturada da cidade. Bairros como Rio Branco, Bela Vista, Petrópolis e Menino Deus têm concentrado interesse imobiliário.
}

atualizados, supõe-se que tais números tenham sido majorados - informação que o Censo Demográfico de 2010 poderá confirmar.

Efetivamente, nos últimos anos, a cidade tem sofrido transformações, sob diferentes aspectos. A mais sensível diz respeito à elevada verticalização e consequente adensamento, permitidos ante os dispositivos em vigor, desde a aprovação do Plano Diretor de Desenvolvimento Urbano Ambiental (PDDUA) de Porto Alegre, em 1999 (PORTO ALEGRE, 2000). Tais transformações têm repercussões do ponto de vista da ambientação urbana, morfologia, circulação, entre outras, refletindo-se no cotidiano de seus moradores particularmente em alguns dos bairros incluídos na Região Centro. O bairro Menino Deus, tipicamente residencial, é caso exemplar dessa situação.

O padrão edilício das ruas do Menino Deus vem sendo alterado. Nas duas décadas de vigência do Plano Diretor de Desenvolvimento Urbano (PDDU), de 1979 a 1999 (PORTO ALEGRE, 1979), ficou consagrada uma tipologia de habitação coletiva caracterizada por edifícios de quatro a, no máximo, seis pavimentos. Esses se mesclaram entre as casas e sobrados dos anos $50 \mathrm{e}$ 60 , constituindo um conjunto harmonioso. A partir do ano 2000, o bairro tornou-se alvo de grandes lançamentos imobiliários, calcados em uma tipologia de edifícios altos, de 14 a 18 pavimentos, com áreas de lazer no térreo. A tendência é a diversificação das opções colocadas nessas áreas coletivas, assim como a sofisticação dos dispositivos de segurança, em detrimento, muitas vezes, de espaços mais amplos nas áreas de uso privativo.

Em pesquisa realizada por Bonorino (2002), que estudou o processo de verticalização no bairro Menino Deus a partir dos anos 90, o autor mapeou todos os prédios com cinco ou mais pavimentos construídos no bairro, no período 1990-2002. Verificou a ocorrência de um processo de aglutinação de lotes - com dimensões originais em torno de $10 \mathrm{~m} \times 30 \mathrm{~m}$ ou $7 \mathrm{~m} \times 35 \mathrm{~m}-$, com a demolição de várias casas, para dar lugar a novos prédios. Constatou que

[ . . . ] o quarteirão que possui o maior número de prédios edificados neste período foi aquele delimitado pelas ruas Múcio Teixeira, Visconde do Herval, e as avenidas Getúlio Vargas e Ganzo [...] (BONORINO, 2002, p. 59).

$\mathrm{O}$ presente trabalho analisa, como estudo de caso, dois quarteirões contíguos desse bairro. Um deles sofreu transformação edilícia significativa (exatamente o quarteirão descrito acima), enquanto o outro permaneceu praticamente inalterado, por se constituir em Área Especial de Interesse Cultural. 
Para tanto, utilizou-se o método de avaliação da QER, desenvolvido por Scussel (2007). Os procedimentos adotados na pesquisa incluem a análise de documentos (planta cadastral da Prefeitura Municipal de Porto Alegre, levantamentos e análises já realizados em relação às escolas e praças); levantamentos a campo, com documentação fotográfica e observação direta; e aplicação do cálculo do Índice de Qualidade do Espaço Residencial.

A Figura 1 apresenta os dois quarteirões tomados como situação exemplar da transformação tipológica que ocorre no Menino Deus. Um deles é conformado pela Av. Bastian, Múcio Teixeira, Av. Ganzo e Av. Getúlio Vargas (ao norte na Figura
1), e integra a Área Especial de Interesse Cultural do bairro; o outro (ao sul na Figura 1) é limitado pelas vias Ganzo, Múcio Teixeira, Visconde do Herval e Getúlio Vargas. Enquanto não se efetiva a regulamentação urbanística dessa área especial, o processo de transformação que vem ocorrendo no bairro, com a construção de espigões, segue pelas adjacências dela.

Levantamento conduzido por Kiefer (2006), que apurou os efeitos da aplicação dos diferentes regimes urbanísticos prescritos pelos planos diretores vigentes a partir de 1959 em Porto Alegre, ilustra as alterações volumétricas promovidas nessa área do bairro Menino Deus, como apresentado na Figura 2.

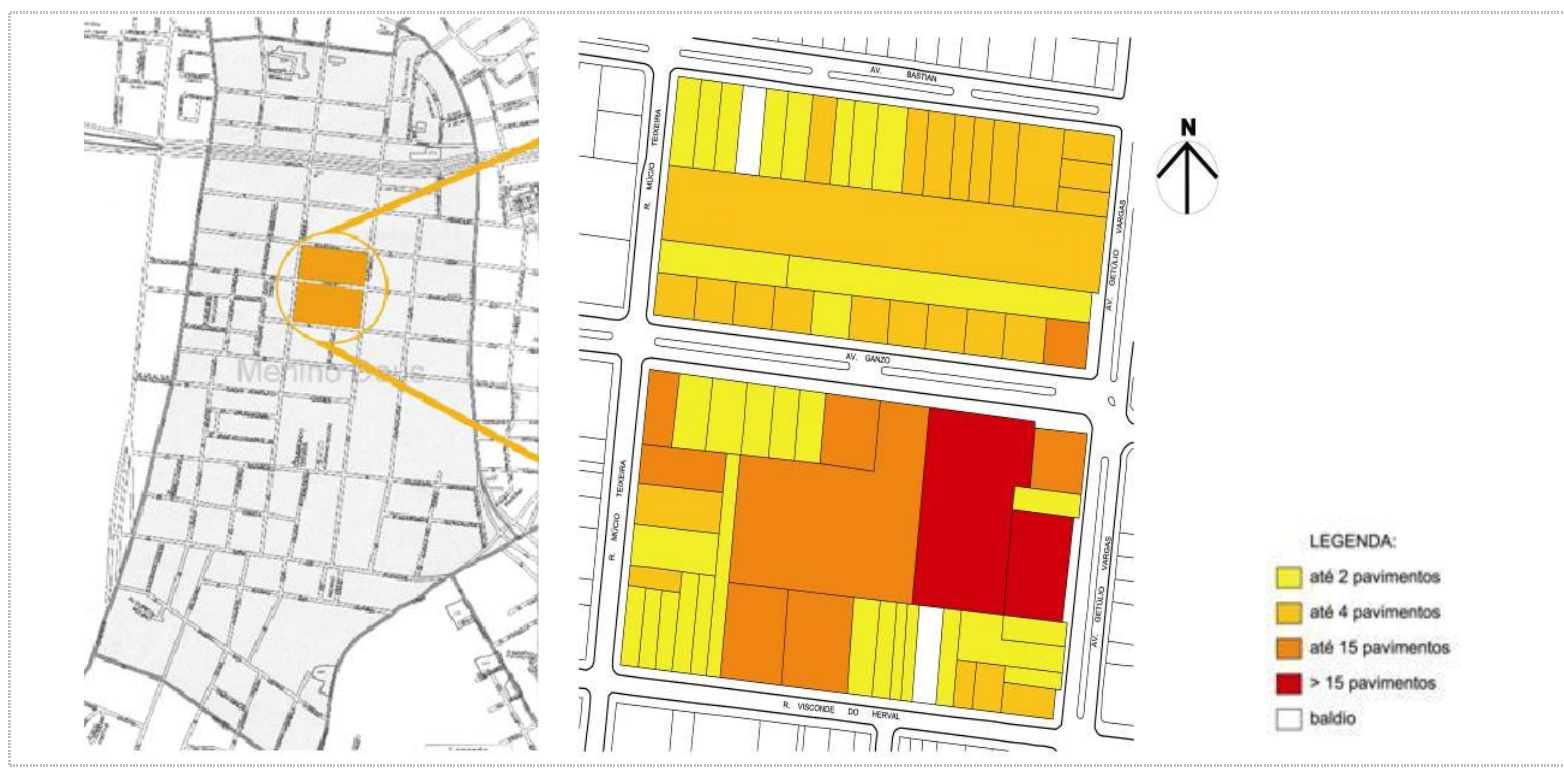

Fonte: Bohadana, Scussel e Sattler (2005).

Figura 1 - Comparação da verticalização em dois quarteirões do bairro Menino Deus

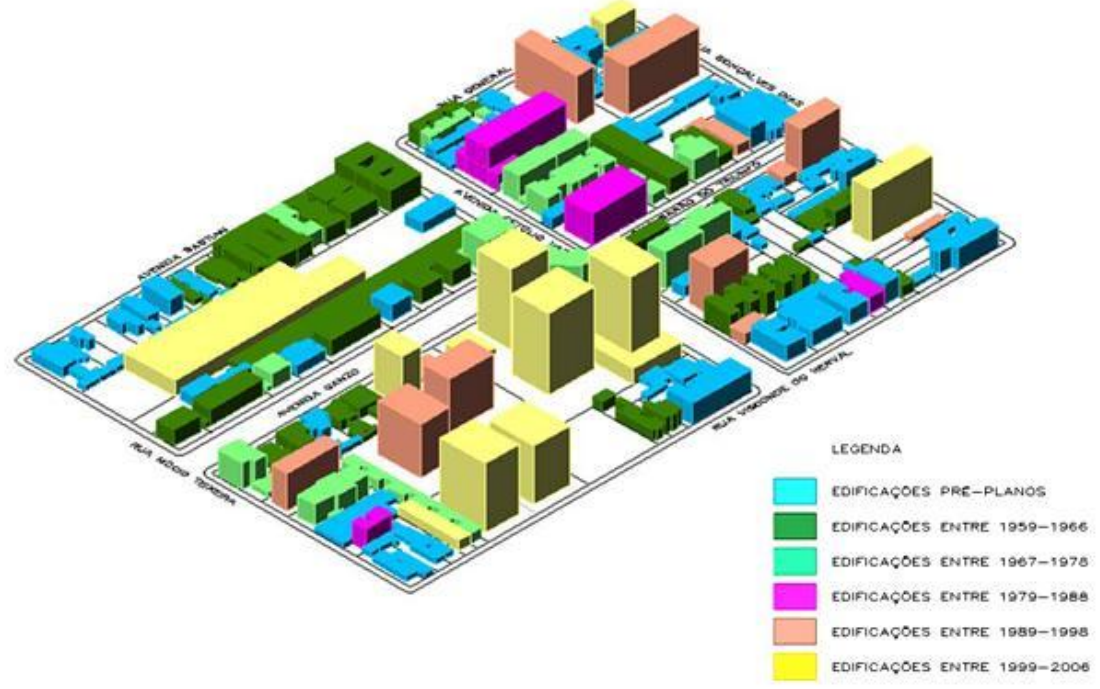

Fonte: adaptado de Kiefer (2006).

Figura 2 - Efeitos da aplicação de diferentes regulamentações urbanísticas no bairro Menino Deus 
Torna-se evidente que, com a multiplicação desse novo padrão de ocupação, não se produz uma transformação apenas morfológica, mas se alteram as próprias características bioclimáticas locais. $\mathrm{Na}$ Figura 3, destaca-se a diferença marcante entre os dois quarteirões analisados, particularmente no que se refere ao sombreamento provocado pelas novas torres de mais de 15 pavimentos.

\section{Método de avaliação da qualidade do espaço residencial}

A qualidade do espaço residencial, ou a qualidade do lugar de morar, é mais bem definida na escala de vizinhança. É nesse nível que se concentrou o trabalho desenvolvido por Scussel (2007), que, ao empreender uma análise crítica de diferentes sistemas de indicadores e modelos de avaliação, internacionais e nacionais, identificou no trabalho de Socco et al. (2002) uma ferramenta aplicável a essa escala: o Índice de Qualidade Ambiental do Espaço Residencial (QSR), que é calculado para cada unidade fundiária ou lote urbano - a menor escala de agregação entre os instrumentos de aferição do espaço intraurbano pesquisados.

A abordagem proposta está assentada numa adaptação do modelo de Socco et al. (2002). A partir daí, Scussel (2007) desenvolveu uma proposição ajustada e ampliada, com base em entrevistas e levantamentos, que buscaram incorporar a percepção do morador e suas práticas cotidianas em seu lugar de moradia. A aplicação desse método oferece, como resultado, uma avaliação da qualidade do espaço residencial em termos de três índices: Índice QER; Índice QER Ajustado; e Índice QER Ampliado (SCUSSEL, 2007).

O presente trabalho se limita à aplicação do Índice QER ao caso estudado, diante do propósito de aferir aspectos de qualificação essencialmente espaciais/ambientais, sem considerar a visão dos moradores.

\section{Índice de Qualidade do Espaço Residencial}

A estrutura de composição do índice $\mathrm{QER}^{2}$ está apresentada na Figura 4.

\footnotetext{
${ }^{2}$ A estrutura de avaliação adotada é, essencialmente, a mesma da composição do QSR, estabelecendo-se adaptações necessárias ao estudo de caso. As principais alterações introduzidas dizem respeito aos critérios de atribuição de valores na avaliação de cada indicador. Permaneceram aqueles que correspondem a
}

A QER é expressa como um índice, obtido a partir da composição de dois outros índices: o índice de Qualidade do Espaço da Habitação (QEH); e o índice de Qualidade do Espaço dos Serviços sociais básicos (QES). Cada um deles, por sua vez, resulta da junção de subíndices. O índice de Qualidade da Habitação (QH) e o índice de Qualidade do Contexto da Habitação (QC) compõem o QEH, enquanto o QES é composto pelo índice de Qualidade dos Serviços (QS) e pelo índice de Qualidade dos Percursos Casa-Serviços (QP).

A obtenção de cada um dos subíndices QH, QC, QS e QP é realizada mediante a aferição de um conjunto próprio de indicadores, que participam com uma ponderação específica no cálculo do respectivo subíndice, conforme o nível de importância que lhes é atribuído.

Cada um dos indicadores pode apresentar um valor bom/ótimo, insuficiente ou péssimo, quantificado segundo critérios preestabelecidos. A escala de valores possíveis, em função da fórmula de cálculo, fica compreendida entre 0,05 e 1,0. Esses estão agrupados em 19 intervalos, aos quais se atribuiu uma cor específica, numa gama de tons, dos vermelhos (mais baixos) aos azuis (mais altos). Desse modo, é possível gerar mapas de valores para cada um dos índices, na área de estudo (SCUSSEL, 2007).

\section{Procedimentos de avaliação do QER}

A operacionalização do cálculo do Índice de Qualidade do Espaço Residencial assenta-se, basicamente, sobre três grandes etapas: levantamento das informações necessárias, ou preparo da base de dados; tabulação dos dados, elaboração do cálculo e mapas de visualização; e análise e interpretação dos resultados.

\section{Levantamento das informações necessárias}

Esta etapa inclui a obtenção da base cartográfica, a identificação dos equipamentos/serviços urbanos que integram a análise, a preparação dos instrumentos de coleta de dados e a execução do levantamento.

referências técnicas consagradas, como é o caso dos raios de influência de equipamentos como escola fundamental e áreas verdes de vizinhança. Além disso, considerou-se que a estrutura, proposta por especialistas, seja uma aproximação otimizada, do ponto de vista técnico, dos requisitos de qualificação dos atributos analisados. No entanto, fez-se necessário conceber uma ordem de valores que refletisse a adequação dos padrões tecnicamente desejáveis à realidade local (SCUSSEL, 2007). 


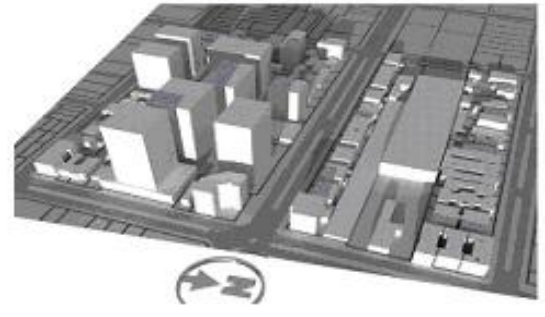

(a)

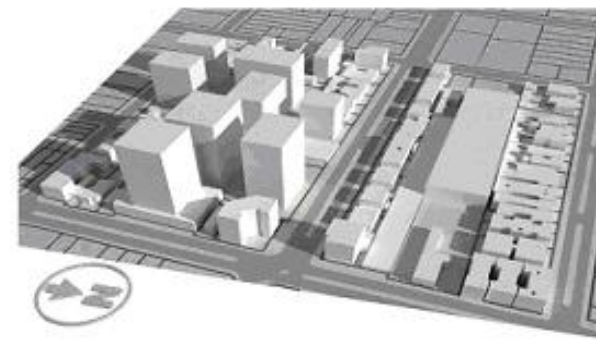

(b)

Fonte: Bohadana, Scussel e Sattler (2005).

Figura 3 - Simulação de sombreamento nos quarteirões estudados: (a) verão/8h e (b) inverno/10h

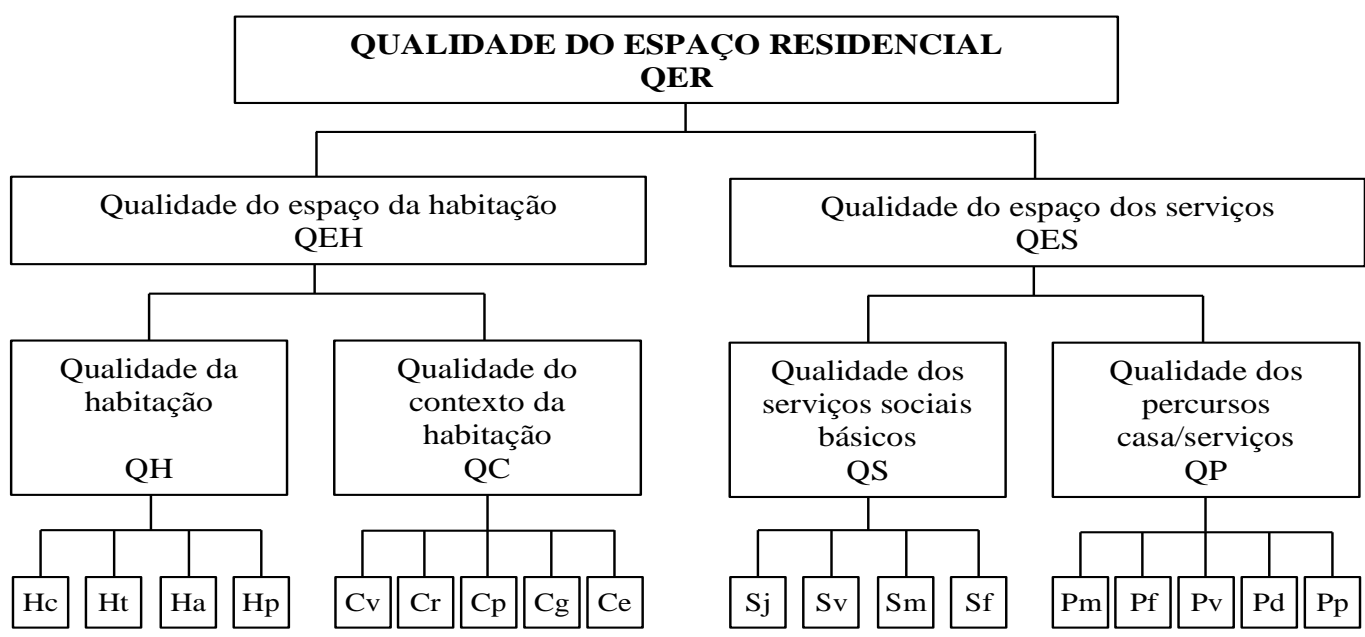

Fonte: adaptação do modelo de Socco et al. (2002)

Legenda:

$\mathrm{Hc}=$ estado de conservação do edifício

$\mathrm{Ht}=$ tipo edilício

$\mathrm{Ha}=$ tipo arquitetônico do edifício

$\mathrm{Hp}=$ qualidade e fruibilidade do espaço pertinente

$C V$ = poluição e interferência do tráfego de veículos

$\mathrm{Cr}=$ presença de atividade de risco ou de atividade geradora de distúrbios

$\mathrm{Cp}=$ qualidade da paisagem perceptível desde a habitação

$\mathrm{Cg}=$ grau de privacidade

$\mathrm{Ce}=$ exposição solar

$\mathrm{Sj}=$ verde de vizinhança para jogos infantis

$\mathrm{S} v$ = verde e esportes de quarteirão

$\mathrm{Sm}=$ escola maternal

$\mathrm{Sf}=$ escola fundamental

$\mathrm{Pm}=$ distância e segurança dos percursos peatonais casa-escola maternal

$\mathrm{Pf}=$ distância e segurança dos percursos peatonais casa-escola fundamental

$\mathrm{Pv}=$ segurança dos percursos casa-áreas verdes e esporte

$\mathrm{Pd}=$ viabilidade, para deficientes físicos, dos percursos casa- escola fundamental

$\mathrm{Pp}=$ qualidade ambiental e paisagística dos percursos casa-escola fundamental

Figura 4 - Estrutura de avaliação do espaço residencial 
Neste estudo de caso, em que uma equipe ${ }^{3}$ esteve encarregada do levantamento, foi fundamental um treinamento prévio, para garantir a uniformidade dos procedimentos e da aplicação dos critérios de avaliação. Sob esse ponto de vista, a documentação fotográfica é um recurso valioso, que permite rever determinados aspectos e dirimir dúvidas, por ocasião do tratamento das informações levantadas a campo.

Além do exame de cada unidade de análise (lote edificado), coletando os dados em ficha de avaliação específica, foram realizados possíveis percursos da residência à escola e à praça, que foram os serviços sociais básicos considerados. ${ }^{4}$ Tais percursos foram registrados fotograficamente, além da observação e de apontamentos em relação ao nível de tráfego, ruído e movimentação das ruas, em horários de utilização desses equipamentos. Estes, por sua vez, também mereceram avaliação em relação às condições de uso, estado de conservação, implantação e ambientação.

Observa-se que os indicadores referentes ao índice QS (qualidade dos serviços sociais básicos) receberam valoração idêntica para unidades que se encontram sob a mesma área de influência dos equipamentos correspondentes. Do mesmo modo, unidades próximas entre si tiveram a mesma avaliação dos indicadores que compõem o índice QP (relativo aos percursos realizados), uma vez que os percursos entre a moradia e os equipamentos são praticamente os mesmos para tais unidades.

\section{Tabulação dos dados, elaboração do cálculo e mapas de visualização}

Para a tabulação dos dados e inserção das fórmulas de cálculo foi utilizado o software SPSS.

A avaliação dos quarteirões estudados seguiu as mesmas ponderações definidas em Scussel (2007):

$$
\begin{aligned}
& \mathrm{QH}=0,40 \mathrm{Hc}+0,22 \mathrm{Ht}+0,23 \mathrm{Ha}+0,15 \mathrm{Hp} \\
& \mathrm{QC}=0,29 \mathrm{Cv}+0,23 \mathrm{Cr}+0,22 \mathrm{Cp}+0,12 \mathrm{Cg}+0,14 \mathrm{Ce} \\
& \mathrm{QS}=0,20 \mathrm{Sj}+0,14 \mathrm{~Sv}+0,33 \mathrm{Sm}+0,33 \mathrm{Sf}
\end{aligned}
$$

\footnotetext{
${ }^{3}$ A avaliação foi realizada em outubro de 2008 , durante a disciplina "Indicadores de sustentabilidade urbana", ministrada pela Prof. ${ }^{a}$ Maria Conceição B. Scussel no Curso de Especialização em Construção Civil do NORIE/PPGEC/UFRGS contando com o trabalho dos alunos Cíntia G. Etges, Nice L. Marques, Tatiane R. M. Pereira, Fernanda R. Ely, Raquel V. Côrtes, Tiziano Filizola, Eliane Diesel, Letícia F. Hoch e Vanessa C. Lugo.

${ }^{4}$ A Escola Estadual de Educação Básica Presidente Roosevelt e a praça Israel são os equipamentos sob cujo raio de influência se encontram os quarteirões analisados e que se localizam em quarteirões adjacentes, junto à área de estudo.
}

$\mathrm{QP}=0,10 \mathrm{Pm}+0,30 \mathrm{Pf}+0,22 \mathrm{Pv}+0,23 \mathrm{Pd}+0,14 \mathrm{Pp}$

$\mathrm{QEH}=0,60 \mathrm{QH}+0,40 \mathrm{QC}$

$\mathrm{QES}=0,60 \mathrm{QS}+0,40 \mathrm{QP}$

$\mathrm{QER}=0,60 \mathrm{QEH}+0,40 \mathrm{QES}$

O mapeamento dos índices foi realizado sobre a base cartográfica existente - planta cadastral em aplicativo Auto CAD, utilizando o software Corel Draw para a colorização dos lotes.

\section{Resultados}

Observando os resultados obtidos para o índice QER nos quarteirões estudados (Figura 5), verifica-se que, de um modo geral, os lotes do quarteirão norte apresentaram índices ligeiramente superiores aos do quarteirão sul. Cabe lembrar, porém, que esse índice faz uma síntese de uma série de indicadores, agregados em subíndices. Decorre daí a importância de se empreender a análise por componentes, ou seja, mediante o exame dos níveis desagregados do índice final, para que se possa identificar quais são os aspectos de qualificação que concorrem mais significativamente para esse resultado.

A análise comparada dos mapas de valores de cada índice permite avaliar quais os aspectos mais críticos ou mais positivos em cada situação.

Tendo em vista que, neste trabalho, interessa aferir o impacto das transformações que vêm ocorrendo ante as alterações patrocinadas pelo PDDUA aumento da taxa de ocupação dos terrenos, do índice de aproveitamento e das alturas máximas permitidas -, a análise dos resultados obtidos será focada para aqueles índices que, dada a natureza de sua composição, tornam-se indicadores mais sensíveis de tais transformações.

Da observação da estrutura de composição do QER, verifica-se que os índices mais afetados são QC (relativo ao contexto da habitação) e QP (relativo à qualidade dos percursos), como se depreende do exame dos indicadores que os constituem: poluição e interferência do tráfego de veículos; presença de atividade de risco ou de atividade geradora de distúrbios; qualidade da paisagem perceptível desde a habitação; grau de privacidade e exposição solar, no caso de QC; distância e segurança dos percursos peatonais casaescola maternal; distância e segurança dos percursos peatonais casa-escola fundamental; segurança dos percursos casa-áreas verdes e esporte; viabilidade, para deficientes físicos, dos percursos casa-escola fundamental; qualidade ambiental e paisagística dos percursos casa-escola fundamental, para aferição de QP. 


\section{MAPA QER}

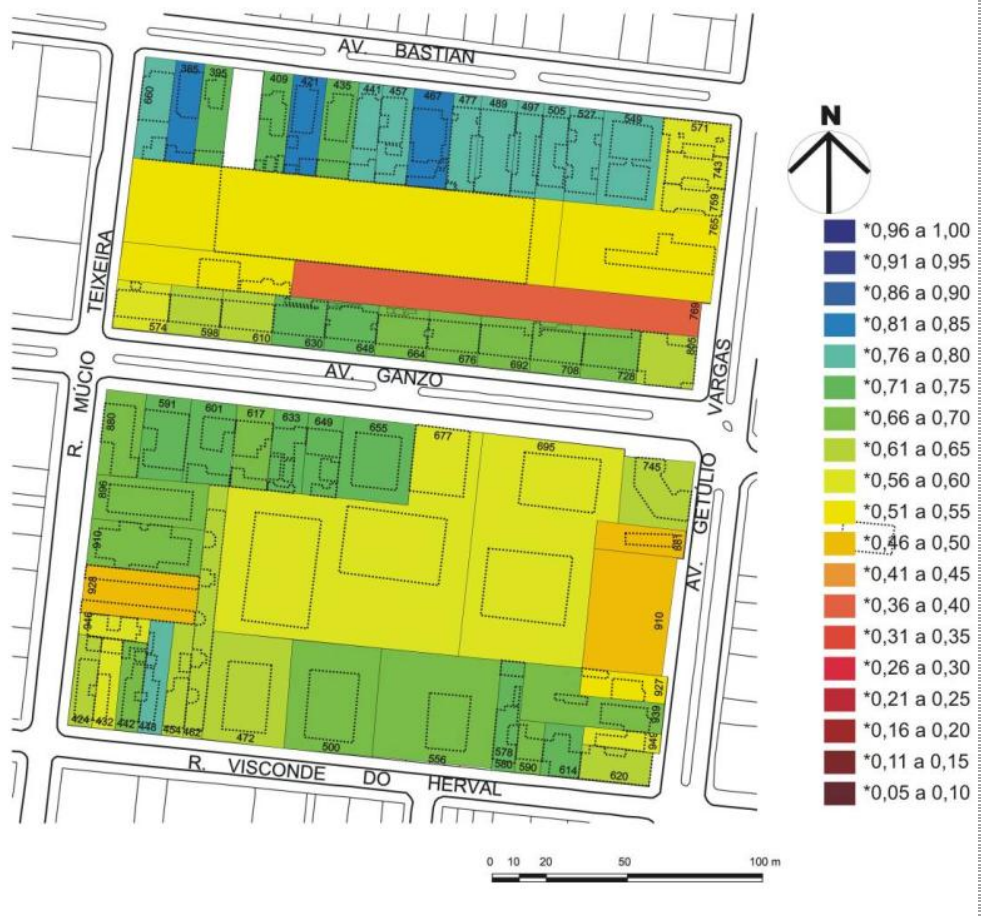

Figura 5 - Mapa de valores do índice de qualidade do espaço residencial QER

Ou seja, a aferição desses indicadores é que atesta o quanto o processo de substituição de edificações por outras de maior porte e altura imprime nova volumetria à conformação da área estudada, estabelecendo novas relações de luz e sombra, reordenando as áreas livres e lindeiras entre os prédios remanescentes, modificando a paisagem, ao mesmo tempo em que incrementa consideravelmente o trânsito e a permanência de veículos nas vias do bairro, introduzindo obstáculos aos percursos de pedestres, além de fatores de risco e/ou desconforto aos moradores.

Nos limites do presente estudo de caso, será detalhado o comportamento das variáveis que constituem o subíndice QC, um dos componentes do índice de Qualidade do Espaço da Habitação. A Figura 6 ilustra as situações que se apresentam ao examinar o desdobramento desse índice QEH, como se descreve a seguir.

Examinando o Mapa QEH, verifica-se que os lotes voltados para a Av. Bastian e a maioria daqueles ao longo da Av. Ganzo têm melhor avaliação. O miolo do quarteirão norte, ocupado por uma loja de grande rede de supermercados, apresenta índice inferior. Ao observar os valores obtidos nos mapas QH e QC, pode-se verificar que é a avaliação obtida em QC a grande responsável pelo "rebaixamento" da pontuação em QEH. Isso significa que os aspectos de qualificação da habitação propriamente dita - nos termos definidos pela estrutura de avaliação - relativos a características da edificação e do interior do lote não se alteram significativamente na comparação dos dois quarteirões. São os aspectos de qualificação de seu contexto imediato que sofrem o impacto da introdução das novas edificações no tecido anteriormente estruturado.

É importante destacar, em relação aos comentários acima, que, uma vez que a ponderação adotada na avaliação privilegia $\mathrm{QH}$ (responsável por 0,60 de $\mathrm{QEH})$, e não QC (responsável por 0,40 de QEH), avaliações mais negativas de QC não têm o mesmo impacto que teriam se houvesse a inversão dessas ponderações.

O exame dos mapas da Figura 6 também permite verificar que as nuances de cores acompanham, de certa forma, os diferentes padrões de estrutura fundiária presentes na área, resultantes da aglutinação de vários terrenos lindeiros, com a finalidade de viabilizar a implantação dos novos empreendimentos.

Em relação ao índice de Qualidade do Contexto da Habitação (QC), a interferência do tráfego de veículos $(\mathrm{Cv})$ existente na Av. Getúlio Vargas e na 
Rua Múcio Teixeira (particularmente nas imediações do supermercado) apresenta nível elevado, com poluição acústica e/ou risco de acidentes. Já na Av. Ganzo, o nível de tráfego é médio, mas há grande demanda por estacionamento, gerando um acúmulo de veículos ao longo de toda a extensão dos passeios, obstruindo, inclusive, passagens rebaixadas para pessoas portadoras de deficiência.

Os lotes ocupados pelo supermercado e respectivo estacionamento apresentam atividades geradoras de distúrbios $(\mathrm{Cr})$, por ocasião da carga e descarga de mercadorias e pela entrada/saída de grande número de veículos. Nesse sentido, é importante destacar que, assim como a implantação de um grande empreendimento de comércio e/ou serviços torna-se fator de dinamização imobiliária em sua região de influência, como ocorreu com o shopping Praia de Belas, em relação ao bairro Menino Deus (BONORINO, 2002), a densificação da região, com a correspondente concentração de pessoas e atividades, atrai novos investimentos dessa natureza - como é o caso do supermercado em pauta.

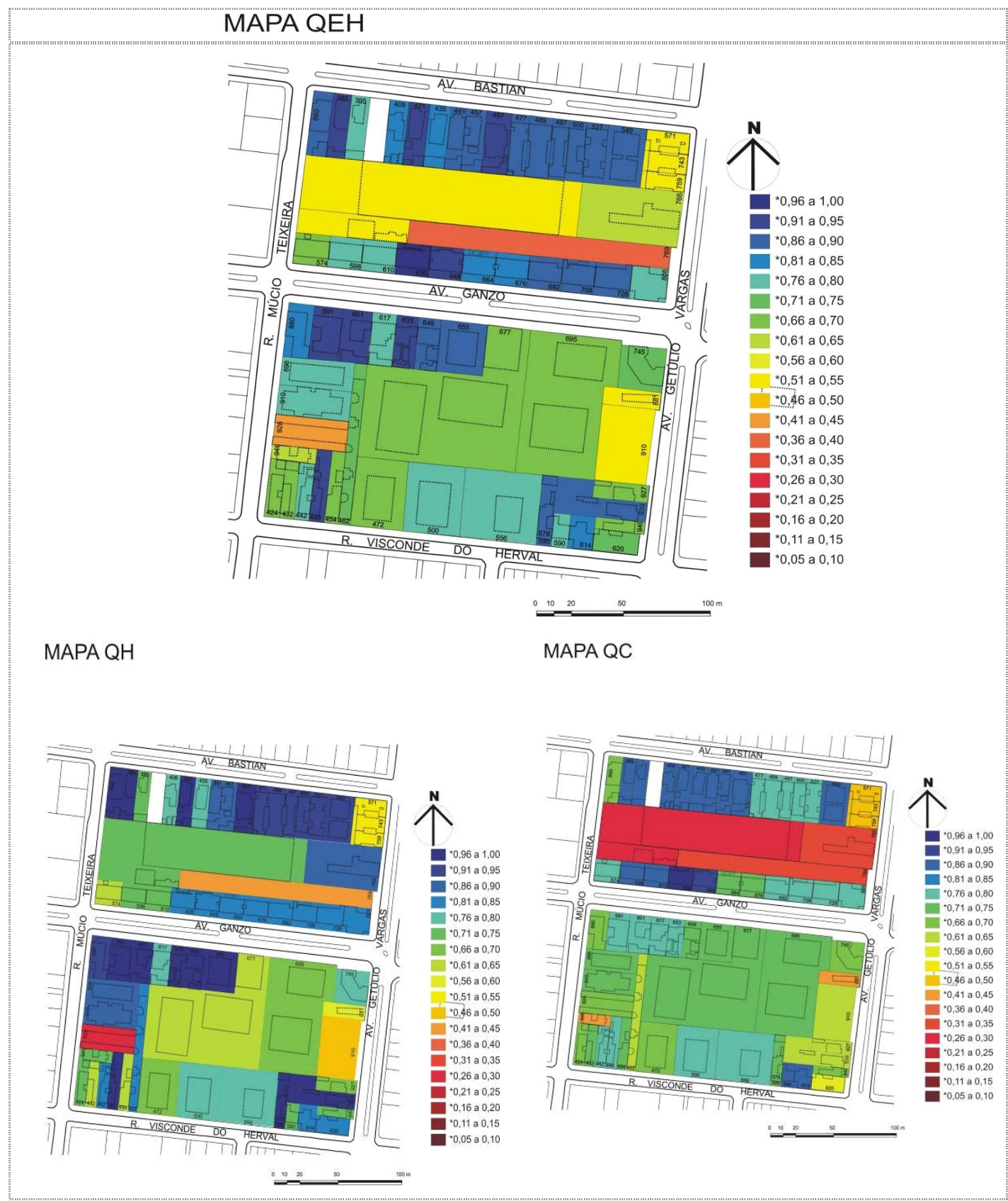

Figura 6 - Mapas de valores do índice de Qualidade do Espaço da Habitação (QEH) e dos subíndices Qualidade da Habitação (QH) e Qualidade do Contexto da Habitação (QC) 
Por oportuno, no que se refere à presença de atividades de comércio e serviços nessa área residencial, cabe apontar que o levantamento identificou um nítido processo de substituição de usos na Av. Bastian em muitos dos antigos sobrados, ocupados agora por escritórios ou serviços especializados. Há que se observar que a mescla de usos é interessante e mesmo propugnada (ALEXANDER, 1977), por trazer o trabalho para junto da habitação, conferindo diversidade ao lugar e reduzindo deslocamentos. Os limites, no entanto, são dados pelo ponto em que a excessiva substituição reverte essa dinâmica, criando espaços sem vida fora do horário comercial, ou introduzindo negócios cujo porte, apesar de trazer facilidades ao bairro, acarreta transtornos significativos para a vizinhança.

A qualidade da paisagem perceptível desde a habitação $(\mathrm{Cp})$ pode ser descrita como um contexto de alto valor arquitetônico ou natural, no caso dos edifícios localizados na Av. Ganzo, em oposição a edifícios de contexto arquitetônico desregrado e de mediana qualidade, localizados na Av. Getúlio Vargas e na R. Múcio Teixeira.

O grau de privacidade $(\mathrm{Cg})$ foi considerado insuficiente na avaliação de muitas unidades, pois as habitações possuem pouco afastamento dos prédios lindeiros e/ou baixa proteção visual em relação ao espaço público e em relação aos outros prédios. Quanto à exposição solar $(\mathrm{Ce})$, as áreas analisadas dividem-se em conceitos bom/ótimo e insuficiente, conforme o posicionamento, orientação solar do lote e proximidade de prédios mais altos.

As edificações mais prejudicadas, no quarteirão sul, ficam junto à via de maior trânsito - Av. Getúlio Vargas - e/ou na área de influência dos prédios mais altos. Destaca-se o caso da unidade

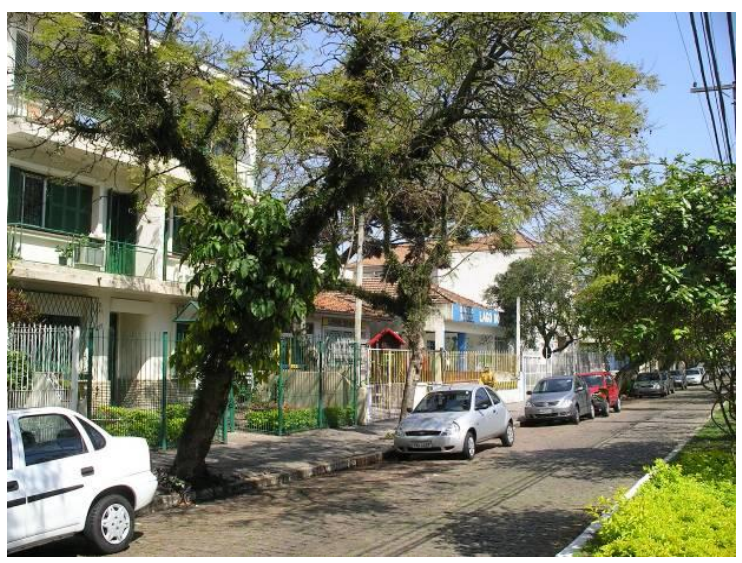

Av. Bastian número 881, por ser uma edificação de dois pavimentos, com uso residencial, e estar cercada por edifícios altos, que acarretam a perda de privacidade e limitam a incidência de iluminação solar direta.

As fotos da Figura 7 ilustram a situação diferenciada do ambiente configurado na Av. Bastian, em que a verticalização está contida (quarteirão norte), e na Rua Visconde do Herval (quarteirão sul), onde a tipologia edilícia original se confronta com torres que impactam diretamente os indicadores de insolação, iluminação e privacidade.

De modo similar, poder-se-ia proceder à decomposição do índice QES (Qualidade do Espaço dos Serviços). Também nesse caso, a ponderação adotada privilegia QS, que contempla os aspectos de qualificação dos equipamentos em que são ofertados os serviços - escola e praça - em detrimento de QP, obtido a partir da composição de indicadores relativos à qualidade dos percursos casa-serviços.

Pode-se afirmar, em relação ao subíndice QP, que, de modo geral, a área estudada foi avaliada positivamente quanto aos percursos casa-serviços, com ligeira superioridade na Av. Bastian. Isso ficou evidenciado nos levantamentos fotográficos realizados (dos quais fazem parte as fotos da Figura 7), que apontaram, no caminho à escola e à praça, ruas bem arborizadas, passeios planos, inclusive com rebaixamento do meio-fio em vários pontos, o que facilita o deslocamento de deficientes físicos. Não é, certamente, uma situação ideal, mas, no contexto urbano de Porto Alegre, a paisagem e a ambientação local são pontos fortes do bairro e, em particular, da área estudada.

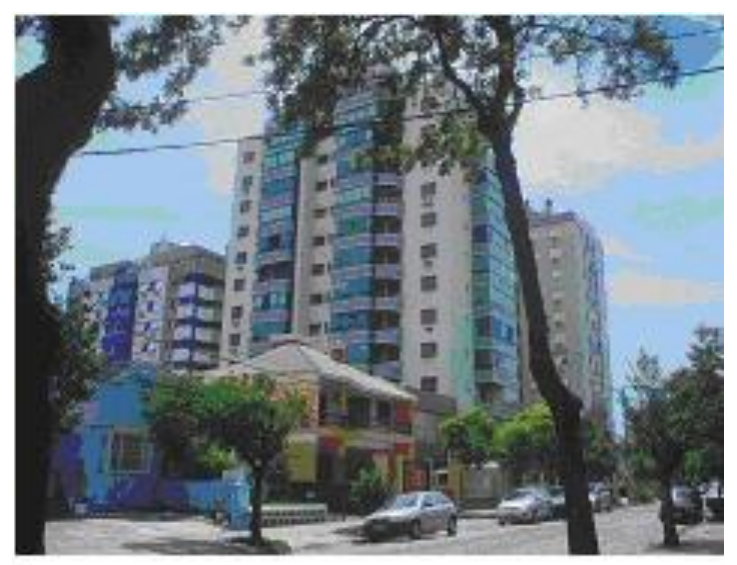

Rua Visconde do Herval

Figura 7 - Qualidade do contexto da habitação: comparação entre Av. Bastian e R. Visconde do Herval 
Não obstante, alguns dos percursos residênciaescola ou praça foram considerados insuficientes ou péssimos, em função da distância a ser percorrida, embora tal situação não constitua a regra. Quanto à qualidade da paisagem $(\mathrm{Pp})$, a maioria dos percursos foi bem avaliada, uma vez que a área é bem arborizada e ainda medianamente tranquila, em que pesem as alterações em andamento. No que diz respeito à segurança, o tráfego mais intenso, nas ruas já apontadas, requer atenção redobrada; além disso, o incremento da população, nas grandes torres, gera maior fluxo de entradas e saídas nos prédios, além de criar maior demanda por estacionamento ao longo das vias. $\mathrm{Na}$ avaliação dos percursos em relação à acessibilidade para portadores de necessidades especiais (Pd), alguns trechos apresentam dificuldades, como calçadas desniveladas, ausência de meio-fio rebaixado para cadeirantes ou canteiros mal dimensionados. Esses efeitos, em relação ao índice QP, se fazem sentir em ambos os quarteirões.

\section{Considerações finais}

A Qualidade do Espaço Residencial, da maneira como foi aqui avaliada, traduz a aferição de atributos de qualificação espacial/ambiental, inerentes a um lugar determinado. São atributos diretamente determinados pelas relações e processos sociais que se estabelecem nesse espaço. Conferem uma identidade própria e peculiar a esse tempo e lugar, assim como às pessoas que aí vivem. Nesse sentido, pode-se entender que as transformações que se vão operando, em virtude das atividades locais e de toda a cidade, têm impacto decisivo na qualidade desses espaços (SCUSSEL, 2007).

Em relação ao método de avaliação aplicado, o fundamental é que se compreenda o comportamento das variáveis que respondem pelos aspectos de qualificação do espaço residencial, e em que medida sua alteração afeta determinada instância de avaliação desse espaço. Algumas características merecem ser destacadas:

(a) a imputação de uma ponderação - seja aos indicadores, seja aos subíndices - implica, sempre, a emissão de um juízo de valor;

(b) a flexibilidade admitida pela estrutura de análise QER propicia que se privilegie um ou outro componente, conforme os objetivos da avaliação; mediante o acréscimo ou a supressão de indicadores, é possível adequar o instrumento a cada realidade;

(c) a aplicação do método pode ter uma utilização também preditiva, na medida em que seja alimentado com informações relativas a alterações a serem introduzidas por projetos existentes; e

(d) uma vez elaborado e tornado público, o Índice de Qualidade do Espaço Residencial servirá como instrumento de participação da população na gestão local.

Retomando os componentes de QER, percebe-se que QC e QP são índices altamente sensíveis às mudanças do tipo das que vêm ocorrendo no bairro Menino Deus. A verticalização acentuada, em meio ao tecido urbano preexistente, o adensamento do tráfego de veículos, o aumento da poluição - do ar, sonora, visual - alteram negativamente os indicadores que compõem esses índices.

Com efeito, a construção de um edifício de 18 pavimentos em um quarteirão de sobrados ou prédios de três pavimentos não somente altera a paisagem do bairro. Reduz (ou até elimina) a intensidade da exposição solar, o grau de privacidade das edificações vizinhas; introduz incremento considerável na densidade populacional, na demanda por serviços e infraestrutura, no fluxo de veículos; afeta, por conseguinte, as próprias relações de vizinhança nos novos prédios, privilegia-se a vida no condomínio, o morador já não sai à rua, os vizinhos não se conhecem. Até que ponto, sob tais condições, a identidade cultural do bairro pode ser sustentada? Em que sentido se alterarão os aspectos de qualificação do lugar de morar de seus habitantes?

Uma aproximação às respostas a tais questões poderia ser alcançada a partir da extensão da investigação realizada, com a aplicação completa do método desenvolvido por Scussel (2007), no sentido de obter o Índice QER Ajustado - que agregaria a percepção e os valores dos moradores à avaliação da qualidade do espaço residencial - e o Índice QER Ampliado - que apontaria as práticas cotidianas de utilização desse espaço.

Tais práticas podem se referir a diferentes aspectos: práticas de utilização dos serviços locais; práticas de deslocamento ou mobilidade; práticas de participação e relações sociais; práticas de hábitos de consumo, de separação de resíduos. Uma vez apuradas, colocariam em evidência aspectos positivos e negativos em relação à direção e à orientação da transformação que vem se concretizando no bairro, particularmente no que se refere ao ambiente construído e aos limites e possibilidades de se efetivarem práticas mais sustentáveis de qualificação do lugar.

Tradicionalmente, os cidadãos não estão afeitos à discussão de normas urbanísticas. No entanto, quando estas se materializam em transformações 
em seu cotidiano, buscam-se mecanismos capazes de viabilizar uma participação mais efetiva na gestão urbana.

O processo de verticalização acentuada que vem ocorrendo nos últimos anos em Porto Alegre tem confrontado os interesses dos diferentes atores envolvidos - empresários da construção, moradores dos bairros mais impactados pelas novas edificações, movimentos ambientalistas, gestores públicos -, pautando recente revisão do PDDUA (PORTO ALEGRE, 2010). Nessa perspectiva, este trabalho pretende ter contribuído para ampliar o conhecimento acerca dos impactos da verticalização e adensamento na qualidade do espaço residencial de Porto Alegre, subsidiando o debate acerca da proposição de padrões urbanísticos e do modelo espacial de desenvolvimento da cidade.

\section{Referências}

ALEXANDER, C. et al. A Pattern Language: un leguaje de patrones. Barcelona: Gili, 1977.

BOHADANA, I.; SCUSSEL, M. C. B.; SATTLER, M. Estudo Comparativo de Verticalização e Densificação no Bairro Menino Deus. Trabalho desenvolvido na Disciplina de Gestão Ambiental Urbana. Porto Alegre: UFRGS/NORIE, 2005.

BONORINO, C. H. Bairro Menino Deus: verticalização no espaço urbano a partir dos anos 90. Porto Alegre: UFRGS, 2002.

CAMPOS FILHO, C. Cidades brasileiras: seu controle ou o caos, o que os cidadãos devem fazer para a humanização das cidades no Brasil. 2. ed. São Paulo: Studio Nobel, 1992.

CAMPOS FILHO, C. Reinvente Seu Bairro: caminhos para você participar do planejamento de sua cidade. São Paulo: Editora 34, 2003.

CORREAA, R. L. Formas Simbólicas Espaciais e Política. In: CONFERÊNCIA INTERNACIONAL ASPECTOS CULTURAIS EN LAS GEOGRAFIAS ECONÓMICAS, SOCIAIS Y POLITICAS, 2007, Buenos Aires. Anais... Buenos Aires: UFF/ Universidad de Buenos Aires, 2007.

DROEGE, P. The Renewable City: a comprehensive guide to an urban revolution. Londres: Wiley-Academy, 2008.
INSTITUTO BRASILEIRO DE GEOGRAFIA E ESTATÍSTICA. Censo Demográfico 2000. Rio de Janeiro: IBGE, 2002a. Disponível em: <http://www.ibge.gov.br>. Acesso em: $12 \mathrm{fev}$. 2003.

KIEFER, F. Estudo de Verticalização da Cidade: o caso de um bairro de Porto Alegre. Relatório de Pesquisa. Porto Alegre: UNIRITTER, 2006.

KOHLSDORF, M. Breve Histórico do Espaço Urbano como Campo Disciplinar. In: FARRET, R. (Org.) $\mathbf{O}$ Espaço da Cidade: contribuição à análise urbana. São Paulo: Projeto, 1985.

LEITE, C. São Paulo: megacidade e redesenvolvimento sustentável, uma estratégia propositiva. Revista Brasileira de Gestão Urbana, São Paulo, v. 2, n. 1, p. 117-126, jan./jun. 2010 .

PORTO ALEGRE. Prefeitura Municipal. Secretaria do Planejamento Municipal. Plano Diretor de Desenvolvimento Urbano. Porto Alegre: CORAG, 1979.

PORTO ALEGRE. Prefeitura Muncipal. Secretaria do Planejamento Municipal. Plano Diretor de Desenvolvimento Urbano Ambiental / PDDUA (Lei comentada). Porto Alegre: PMPA Coordenação de Comunicação Social, 2000.

PORTO ALEGRE. Prefeitura Muncipal. Secretaria do Planejamento Municipal. Lei Complementar $\mathbf{n}^{\mathbf{0}}$ 646, de 22 de julho de 2010 - Altera e inclui dispositivos, figuras e anexos na Lei Complementar $n^{\circ} 434$, de $1^{\circ}$ de dezembro de 1999; Plano Diretor de Desenvolvimento Urbano Ambiental de Porto Alegre (PDDUA) e alterações posteriores, e dá outras providências.

ROAF, S.; CRICHTON, D.; NICOL, F. Adapting Buildings and Cities for Climate Change: a $21 \mathrm{st}$ century survival guide. Oxford: Architectural Press, 2009.

RUEDA, S. Modelos de Ordenación del Território Más Sostenibles. Barcelona: [s.1.], 2002.

RYKWERT, J. A Sedução do Lugar: a história e o futuro da cidade. São Paulo: Martins Fontes, 2004. 
SALINGAROS, N. Connecting the Fractal City. Barcelona, Abril 2003. (Keynote speech, 5th Biennial of towns and town planners in Europe). Disponível em:

<http://www.math.utsa.edu/sphere/salingar/contr.a rch.html>. Acesso em: 13 ago. 2006.

SATTERTHWAITE, D. Como as Cidades Podem Contribuir para o Desenvolvimento Sustentável. In: MENEGAT, R.; ALMEIDA, G. (Org.). Desenvolvimento Sustentável e Gestão Ambiental nas Cidades: estratégias a partir de Porto Alegre. Porto Alegre: Editora da UFRGS, 2004. p. 129-169.

\section{SCUSSEL, M. C. B. O Lugar de Morar em} Porto Alegre: uma abordagem para avaliar aspectos de qualificação do espaço residencial, à luz de princípios de sustentabilidade. 2007. Tese (Doutorado em Engenharia Civil) - Programa de Pós-Graduação em Engenharia Civil, Universidade Federal do Rio Grande do Sul, Porto Alegre, 2007.

SOCCO, C. et al. Indice di Qualità Ambientale dello Spazio Residenziale. Torino: Politecnico e Università di Torino, 2002. Disponível em: <http://www.ocs.polito.it>. Acesso em: 11 mar. 2002.
SOMEKH, N. A Cidade Vertical e o Urbanismo Modernizador. São Paulo: Studio Nobel; FAPESP, 1997.

SOMEKH, N.; LEITE, C. Implementing Urban Change. In: URBAN AGE SOUTH AMERICA CONFERENCE, 2008, São Paulo. Essays...

Londres: London School of Economics, 2008. Disponível em:

<http://www.urbanage.net/0_downloads/archive/_ SA/17_NewsPaper_Essay_Somekh-Leite.pdf $>$. Acesso em: 25 jun. 2010.

SOUZA, M. A. A identidade da Metrópole: a verticalização em São Paulo. São Paulo: EDUSP, 1994.

VILLAÇA, F. Espaço Intra-Urbano no Brasil. São Paulo: Studio Nobel, 1998.

\section{Agradecimentos}

Os autores agradecem aos alunos do NORIE/PPGEC envolvidos na pesquisa e à bolsista de Iniciação Científica, Ana L. Seixas, pela colaboração recebida. 